\title{
IMPLEMENTASI MODEL MANAJEMEN STRATEGIS DAN OPERASIONAL BERBASIS KINERJA DI FAKULTAS EKONOMI UNDIKSHA
}

\author{
Naswan Suharsono \\ Jurusan Pendidikan Ekonomi \\ Universitas Pendidikan Ganesha \\ Singaraja, Indonesia \\ e-mail: genotsuharsono@gmail.com
}

\begin{abstract}
Abstrak
Penelitian ini merupakan usaha lanjutan untuk mengimplementasikan Sistem Manajemen fakultas berbasis Rencana Strategis (Renstra) dan strategi pencapaiannya melalui Rencana Operasional (Renov) sampai jangka waktu 2025. Tujuan operasional penelitian ini adalah mendapatkan informasi yang menjadi komponen kunci dari lapangan untuk keperluan pengadaan basis data yang dibutuhkan fakultas, standar layanan informasi terpadu, dan hasil implementasi sistem administrasi operasional sampai ke manajerial fakultas dalam melaksanakan tridarma. Pengumpulan data dilakukan dengan teknik survay, observasi, dan dokumentasi pada 5 jurusan di lingkungan Fakultas Ekonomi. Adapun data yang didapatkan diolah dengan teknis deskriptif dan analisis SWOT yang hasilnya bisa digunakan sebagai dasar mengimplementasikan Rencana Strategis dan Operasional yang telah dihasilkan pada penelitian tahun pertama. Hasil penelitian menunjukkan bahwa, pertama basis data pendukung manajerial dan operasional yang diperlukan untuk mengembangkan prodi di setiap jurusan untuk memenuhi kebutuhan guru dan SDM pelaku kegiatan ekonomi di dunia usaha dan industri (DUDI) terus meningkat. Kedua, tatalaksana administrasi input-proses-output informasi manajemen berbasis teknologi informasi (TI) di lingkungan FE untuk menunjang kegiatan pembelajaran dan administrasi program belum optimal. Ketiga, kinerja dosen dan pegawai administrasi fakultas berbasis TI bervariasi volume dan mutunya. Keempat, pola manajemen waktu kegiatan organisasi kemahasiswaan di bidang ekstra-akademik berbagi dengan tupoksi. Kelima, kinerja civitas akademika untuk menghasilkan output institusi sesuai profil lulusan telah ditetapkan dan direalisasikan dalam pelaksanaan kurikulum program studi. Direkomendasikan agar usaha untuk peningkatan kinerja disinergikan dengan peningkatan status akreditasi program studi dan AIPT.
\end{abstract}

Kata Kunci: manajemen berbasis kinerja, produk tridharma, administrasi kepegawaian, kinerja organisasi, rencana strategis

\begin{abstract}
This research is a further effort to implement Management System of faculty based on Strategic Plan (Renstra) and its achievement strategy through Operational Plan (Renov) until 2025. The operational objectives of this research are to obtain information that becomes a key component of the field for the need of procurement of database needed by faculty, integrated information service standard, and implementation result of operational administration system to faculty managerial in implementing tridarma. The data was collected by surveys, observation, and documentation in 5 departments within the Faculty of Economics. The data obtained is processed by technical descriptive and SWOT analysis which the result can be used
\end{abstract}




\begin{abstract}
as the basis for implementing Strategic and Operational Plan which has been produced in first year research. The result of the research shows that the first data base of managerial and operational support needed to develop study program in every department to fulfill requirement of teacher and human resources of business actor in industry and industry (DUDI) keep increasing. Second, the administrative management of input-process-output management information-based information technology (IT) in the FE environment to support learning activities and program administration has not been optimal. Third, the performance of faculty members and administrators of IT-based faculty vary in volume and quality. Fourth, the time management pattern of student organization activity in the extra-academic field is shared with tupoksi. Fifth, the performance of the academic community to produce the institution output according to the graduate profile has been established and realized in the implementation of the study program curriculum. It is recommended that efforts to improve performance are synergized with the improvement of the accreditation status of the study program and AIPT.
\end{abstract}

Keywords: performance-based management, tridharma products, personnel administration, organizational performance, strategic plans

\section{PENDAHULUAN}

Sistem administrasi fakultas di lingkungan Kemenristek-Dikti menunjukkan bahwa ada dua dimensi manajemen-strategis dan multidimensi sehingga harus dijabarkan lebih lanjut dalam rencana-rencana operasional, yaitu kegiatan akademik dan non-akademik. Dalam kaitannya dengan dimensi-dimensi akademik dan non-akademik, hasil penelitian Suharsono (2016) menunjukkan bahwa platform pengembangan $\mathrm{FE}$ UNDIKSHA ke depan, baik yang berkaitan dengan dimensi akademik maupun dimensi non-akademiknya adalah, meningkatkan daya saing produk pendidikan dengan mengimplementasikan SPMI yang terstruktur dan berkelanjutan. Kedua, mengimplementasikan iklim kehidupan akademik untuk menciptakan kehidupan masyarakat kampus yang cerdas dan bertata nilai. Ketiga, mempercepat peningkatan peringkat UNDIKSHA dalam konstalasi mutu Universitas Nasional yang mandiri melalui penyusunan dan pengembangan Standar Akademik. Keempat, berperan aktif dalam upaya pembangunan tatanan masyarakat ilmu pengetahuan yang berpegang teguh pada prinsip-prinsip dasar Pancasila dan UUD 1945, serta nilai-nilai luhur budaya bangsa. Kelima, menghasilkan produk lulusan yang dapat mengamalkan ilmu pengetahuan dan keterampilan yang didapatkan, dengan standar ilmiah dan etika akademik yang mapan.

$$
\text { Adanya kelima platform }
$$
pengembangan $\mathrm{FE}$ di atas, maka langkah awal yang perlu segera dilakukan adalah upaya perekayasaan tiga pilar utama sistem pendidikan tinggi, yaitu pertama, pengembangan kurikulum multi-entrymulti-eksit dengan perangkat pendukung instrumental inputnya. Kedua, pengembangan sistem manajemen akademik dan manajemen umum yang dapat meningkatkan produktivitas kinerja proses layanan pendidikan civitas akademika secara sinergis dan berkelanjutan, dengan dukungan teknologi informasi yang sesuai. Ketiga, pengayaan pengalaman belajar mahasiswa baik pada dimensi akademik, personal, sosial, maupun profesional agar para alumni FE dapat bersaing di pasar global dan bisa memberi sumbangan optimal bagi upaya memajukan kehidupan bangsa.

Penelitian ini difokuskan pada usaha mengimplementasikan alternatif model sistem e-manajemen akademik dan emanajemen institusi (umum dan keuangan) yang bisa disinergikan kinerjanya sehingga bisa mencapai hasil yang optimal. Sistem manajemen ini akan dikembangkan untuk masa siklus satu tahun anggaran, dengan output sistem dalam bentuk data-base, buku panduan prosedur operasional standar (POS), dan 
prototipe model Manajemen FE berbasis kinerja dan Teknologi Informasi.

Penelitian ini difokuskan pada usaha mengembang model manajemen akademik dan institusi perguruan tinggi yang relevan dengan pembukaan prodi baru dan ketersediaan laboratorium sarana belajar yang dapat mendukung pengembangan kompetensi lulusan yang siap memenuhi kebutuhan masyarakat DUDI bidang jasa, dagang, dan industri strategis Indonesia 5-10 tahun mendatang. Model itu sendiri memerlukan informasi yang secara empirik akurat adanya di lapangan dan bisa digunakan sebagai dasar pertimbangan yang secara ilmiah bisa dipertanggung jawabkan kebenarannya.

Sebagai bagian dari upaya menurunkan rancangan strategis Universitas dan media penghubung ke Renstra dan Renop program-program studi yang ada di lingkungan FE UNDIKSHA, hasil penelitian kebijakan ini merupakan salah satu dokumen penting untuk pengembangan fakultas di masa depan. Hasil penelitian ini juga dapat digunakan sebagai landasan pijak bagi penyiapan sarana-prasarana fakultas dan rekruitmen kepegawaian (staf dosen dan tenaga kependidikan) sesuai kualifikasi yang dituntutkan dalam Rencana Induk Pengembangan (RIP) fakultas.

\section{TELAAH RITERATUR}

\section{Struktur Keilmuan Ekonomi}

Berdasarkan analisis stuktur dasar disiplin ilmu ekonomi dan hasil-hasil studi kelayakan kebutuhan riel di masyarakat dunia usaha dalam lima tahun terakhir ini, maka Visi Fakultas Ekonomi dan Bisnis yang tertuang dalan Naskah Akademik Pendirian FE Undiksha (2012) dan draft perbaikannya (2015) adalah menjadi "pusat keunggulan dan rujukan pengembangan pendidikan ekonomi, bisnis dan kewirausahaan berkarakter". Visi ini sangat mendukung visi Undiksha untuk menjadi perguruan tinggi rujukan dalam bidang pendidikan dan Ipteks berlandaskan Pancasila dan kearifan lokal tri hita karana. Adapun misi Fakultas
Ekonomi dan Bisnis Undiksha adalah:"menyelenggarakan program akademik, vokasi dan profesi bidang pendidikan ekonomi dan bisnis, serta mengimplementasikan budaya wirausaha mandiri"

Dengan visi dan misi itu, pengembangan fakultas akan mengacu pada dua disiplin keilmuan dengan pola ilmiah pokok ilmu pendidikan dan ilmu ekonomi dari teori ke aplikasi. Masuknya dua konsorsium disiplin ilmu dasar dalam suatu fakultas sekaligus, akan memungkinkan dikembangkannya program-program aplikasi di bidang pendidikan kewirausahaan (entrepreneurship education) yang didukung dengan pengembangan staff, kurikulum dan perangkat kompetensi bidang studi baik di program-program studi kependidikan maupun nonkependidikan. Inilah yang menjadi ciri khas dari kehadiran Fakultas Ekonomi era perluasan mandat Undiksha dan pembeda esensi misinya dengan Fakultas Ekonomi yang terlahir langsung dari universitas murni yang sudah ada.

Dalam upaya mencapai misi di atas, maka dipandang perlu diadakan penelitian pengembangan yang berkaitan langsung maupun tidak langsung dengan rencana strategis pengembangan FE dalam 5-10 tahun mendatang. Secara khuus, penelitian kebijakan ini dilakukan untuk mendapatan informasi yang mutakir, akurat dan berkesesuaian dengan:

1) Pembukaan dan pengembangan program-program studi baru yang relevan dengan kebutuhan riel masyarakat Bali dan Indonesia pada umumnya

2) Pengembangan laboratorium $\mathrm{FE}$ terpadu yang didasarkan pada seperangkat tata-nilai, konsep, prinsip, hukum, dan teori yang memiliki relevansi dengan realitas kehidupan ekonomi dan bisnis pada skala lokal, nasional, maupun internasional.

Perumusan tujuan Pendidikan FE di atas akan digunakan sebagai dasar perumusan tujuan-tujuan pendidikan pada tingkat program studi sehingga ada variasi 
pada tingkat sesuai dengan karakteristik jenis profesi yang hendak dicapai. Perumusan tujuan pendidikan pada tingkat fakultas itu selanjutnya akan menjadi dasar dalam penyusunan Profil Prodi di lingkungan FE Undiksha, Berikut adalah kerangka teoritik dan kajian empirik yang relevan.

\section{DUDI dalam Pembangunan Ekonomi}

DUDI merupakan bagian integral dari tata-kehidupan sosial ekonomi masyarakat yang telah banyak menyumbang bagi kemajuan peradaban manusia sedemikian rupa sehingga menjadi issu yang tetap dinamis dan aktual. Hasil-hasil kajian teoretis-historis menunjukkan adanya hubungan kausalitas antar dimensi kehidupan manusia, alam dan lingkungan hidupnya. Riset mendalam yang dilakukan Weidenfild dkk (2010) terhadap para manajer industri wisata dan 435 wisatawan yang datang ke England menunjukkan adanya keeratan interelasi antara jenis produk yang ditawarkan, kluster ruang, dan perilaku DUDI.

Dari aspek promosi, kata kuncinya adalah citra wisatawan terhadap tempat tujuan wisata (destination image). Secara teoretik, kesan yang dimaksud adalah 'the expression of all objective knowledge, impressions, prejudice, imaginations, and emotional thoughts an individual or group might have of a particular place' (Lawson and Bovy, 2007). Itulah sebabnya maka pada tahapan awal dari upaya pembangunan DUDI adalah melakukan evaluasi diri (self-evaluation) terhadap apa yang sedang berjalan. Dari hasil evaluasi yang obyektif dan benar itulah, upaya percepatan dan perluasan dilakukan dengan dukungan kebijakan yang tepat waktu dan tepat sasaran.

Pertanyaannya adalah, indikatorindikator kunci apa yang bisa digunakan untuk mengukur ketepatan kebijakan DUDI? Salah satu kuncinya adalah jaminan perlindungan terhadap sistem nilai religiusitas tempat tujuan wisata, dan kemudahan saat menjalankan peribadatan baik wisatawan maupun pelaku bisnis DUDI saat berada di wilayah kerja operasional perusahaan. Hasil studi kasus Hamira Zamani-Farahani dan Henderson (2009) di Iran dan Saudi Arabia menunjukkan adanya pengaruh kegiatan agama negara terhadap perkembangan DUDI. Juga ada interaksi antara kebijakan pemerintah, pola manajemen pemasaran dan pelibatan masyarakat dalam penyelenggaraan kegiatan DUDI. Dengan demikian, maka di satu sisi, kegiatan upacara ritual keagamaan bisa menjadi events DUDI unggulan tanpa harus mengintervensi prosesinya. Di sisi lain, wisatawan juga merasa nyaman untuk melakukan kebutuhan religiusnya di daerah tujuan wisata.

3.3 Aplikasi Manajemen Strategis di PT dan DUDI

Untuk memfasilitasi terjadinya proses pengembangan kompetensi wirausaha skala mikro, kecil dan menengah (UMKM) Suharsono dkk. (2006, 2007, 2015) telah melakukan usaha mengimplementasikan model pembelajaran inovatif dalam upaya menumbuhkan budaya kewirausahaan. Hasil penelitian menunjukkan rekomendasi agar bahan belajar didisain melalui program e-learning sehingga bisa diakses para pengguna secara lebih produktif dan efisien. Dari Hasil penelitian (Suharsono dkk. 2009) ditemukan adanya pengaruh yang signifikan dari usaha menyelesaikan tugas latihan terhadap kemajuan belajar bertindak wirausaha. Hal ini menunjukkan adanya sinergi kinerja komponen multimedia dapat meningkatkan kadar interaktif, kemandirian dan usaha belajar melakukan tindakan usaha.

Program ini terdukung oleh meningkatnya motivasi mereka berada di lapangan dan adanya dukungan positif dari Asosiasi Pengusaha (Suharsono dkk, 2008). Hasil implementasi lanjutan (Suharsono dkk. 2009) menunjukkan bahwa keefektivan kinerja program pelatihan kewirausahaan dapat ditingkatkan melalui sinergi dalam keterpaduan. Namun, kekurang siapan dalam mengikuti irama budaya kerja dunia usaha ternyata telah mengkontribusi 
kekurang berhasilan kinerja secara keseluruhan. Dalam konteks inilah, pengembangan Wisata Dharma perlu didesain dan diapkan sebagai lahan kerjasama antara pemerintah, dunia usaha, dan masyarakat pendukung lingkungannya. Di lingkungan DUDI yang bersiklus perintisan, pengembangan dan pendewasaan berulang itulah jiwa wirausaha terus tumbuh-kembangan sesuai tuntutan zamannya.

\section{METODOLOGI}

Secara umum, metode penelitian mengikuti tahapan alur penelitian kebijakan untuk mendapatkan data dan informasi kegiatan dan hasil implementasi Renstra dan Renop fakultas yang sedang disempurnakan. Kegiatan penelitian dimulai dari tahap evaluasi dan identifikasi lapangan untuk mendapatkan peta kondisi terakhir perwajahan manajemen akademik dan manajemen institusi UNDIKSHA dan pemahaman terhadap kualitas layanan yang ada, dilanjutkan ke pembuatan instrumen penelitian disertai ujiimplementasi dan revisi. Pada tahap ketiga, rancangan model kebijakan dicarikan rujukannya di lapangan dengan menempatkan peneliti sebagai partisipan aktif dalam kegiatan penelitian.

Penelitian ini mangambil lokasi di FE UNDIKSHA, dengan mengambil setiap program studi di FE sebagai satuan subyeknya. Pengumpulan data dilakukan dengan teknik survay, observasi, dan dokumentasi kegiatan manajemen di 5 sampel subyek program studi terkait pelaksanaan manajemen akademik perkuliahan dan manajemen program tata pamong. Adapun analisis data yang digunakan untuk menentukan prioritas unggulan dan analisis kebijakan menggunakan analisis gabungan antara metode AHP (Analytical Hierarchy Process), SWOT, analisis komponen dan Analisis Isi.

Analisis isi digunakan untuk mendapatkan informasi tentang muatan konten setiap produk, sedangkan AHP dan SWOT digunakan untuk menentukan status hasil evaluasi, sekalus sebagai dasar perumusan rancangan alternatif kebijakan pengembangan DUDI. Data pendukung lainnya akan dicari dan dianalilis dengan analisis kompomen, deskriptif, dan analisis statistik disesuaikan dengan keperluan evaluasi sub-sub domain bidang yang akan didesain, diuji-coba, direvisi, dan diimplementasikan pada obyek bidang garapan menuju tercapainya target luaran produk penelitian yang ditargetkan. Atas dasar hasil-hasil analisis data tersebut, selanjutnya digunakan untuk menyusun rencana kerja operasional setiap awal tahun.

\section{HASIL DAN PEMBAHASAN}

Sebagaimana telah dipaparkan dalam permasalahan, penelitian yang diajukan adalah, bagaimana pengaruh kebijakan manajemen FE terhadap kinerja dosen, pegawai dan mahasiswa? Apakah implementasi sistem Administrasi berbasis Teknologi Informasi di fakultas bisa bekerja sinergis dengan SIAK UNDIKSHA dan bisa sejalan dengan renstra Fakultas?

Hasil penelitian menunjukkan bahwa, kenyataannya Beban Kerja dosen melebihi di bidang pendidikan, tetapi kurang di bidang penelitian dan P2M. Hal ini terjadi karena banyaknya kelas yang diampu. Oleh karena itu, fakultas bersama rektorat memasukkan sistem insentif kelebihan mengajar yang memadai dalam format remunerasi. Demikian juga adanya dukungan penyediaan basis data pendukung manajerial dan operasional yang diperlukan untuk mengembangkan prodi di setiap jurusan untuk memenuhi kebutuhan guru dan SDM pelaku kegiatan ekonomi di dunia usaha dan industry (DUDI) terus meningkat.

Kelemahan utama penyelenggaraan layanan pendidikan di FEB selama ini adalah kurangnya Jumlah dan mutu staf Fakultas yang sesuai dengan bidang studi. Kondisi internal ini menyebabkan sulitnya ruang gerak dalam pengelolaan organisasi dan pengembangan diri dosen. Namun hal ini dapat teratasi dengan pemanfaatan sumber daya dari Fakultas lain atau sharing dengan Fakultas lain yang 
relevan. Harapan untuk dapat meningkatkan kuantitas dosen Fakultas diserahkan kepada kebijakan pemerintah untuk pengangkatan staf dosen baru. Akomodasi dengan pihak pengguna lulusan yang sudah diselenggarakan selama ini masih harus ditingkatkan untuk penyempurnaan penyelenggaraan pendidikan dalam menghasilkan tenaga profesional di bidang ekonomi dan bisnis sesuai dengan kebutuhan pengguna lulusan.

Demikian juga halnya dengan ketersediaan sarana dan prasarana pendidikan menjadi kelemahan diakibatkan dari pemanfaatan yang padat sehingga perlu untuk ditingkatkan baik kualitas maupun kuantitasnya. Keterbatasan sarana dan prasarana juga diakibatkan oleh perkembangan teknologi mengingat jurusan yang berada di lingkungan fakultas ekonomi dan bisnis merupakan jurusan dengan bidang ilmu yang berkembang sejalan dengan perkembangan teknologi yang mengharapkan lulusan tidak gagap akan perkembangan teknologi. Keterbatasan ruang kuliah menjadi permasalahan yang cukup mengkhawatirkan terjadi saat ini sehingga harus menjadi bahan evaluasi untuk kedepannya mengingat peminat dari jurusan-jurusan di lingkungan fakultas ekonomi dan bisnis ini semakin meningkat. Kecukupan dana juga merupakan salah satu permasalahan mengingat banyaknya aktivitas dan keperluan akan sarana dan prasarana yang tinggi sedangkan alokasi dana yang ada terbatas jumlahnya.

Kedua, Kinerja Pegawai mengikuti 'arah angin', yaitu tupoksi dan kebijakan manajerial, khususnya kebijakan kepegawaian dan keuangan kelembagaan sehingga kinerjanya bisa ditingkatkan melalui sosialisasi aturan dan promosi jabatan karena terbukti sebagian dari mereka kurang memahami tupoksi dan terget capaian produknya. tatalaksana administrasi input-proses-output informasi manajemen berbasis teknologi informasi (TI) di lingkungan FE untuk menunjang kegiatan pembelajaran dan administrasi program belum optimal. Hasil analisis SWOT menunjukkan bahwa ada indikasi semangat kerja yang berbeda antara PNS dan pegawai kontrak dikarenakan adanya perbedaan status, kemanaman dan kenyamanan jabatan yang sedang diampu sekarang.

Ketiga, kinerja pegawai administrasi fakultas berbasis TI bervariasi volume dan mutunya. Hasil wawancara dengan perwakilan pegawai PNS dan pegawai kontrak menunjukkan tingkat perbedaan motivasi dan semangat juang untuk bisa sukses berkarier di lembaga pendidikan dan dunia usaha.

Keempat, pola manajemen waktu kegiatan organisasi kemahasiswaan di bidang ekstra-akademik berbagi dengan tupoksi. Kinerja Mahasiswa 'out of focus', kurang pembinaan terkait tugas utamanya (kuliah, SKPI, Sertifikat kompetensi). Pada hal, potensi dan bakat bawaan dari SLTA dan talenta Luar Biasa. Solusinya adalah harus dikeluarkan Surat-surat Edaran Dekan yang di satu sisi mereka secara organisatoris maupun perorangan yang bisa mengarahkan kegiatan organisasi kemahasiswaan (ORMAWA) bisa menjadi lahan untuk berlatih dan berbagi dan meninggalkan budaya berebut dan saling menjatuhkan sesama kawan. Oleh karena itu, peran wakil Rektor dan wakil dekan bidang pembinaan sivitas academika mahasiswa menjadi lebih kondusif dan optimaql

Kelima, kinerja civitas akademika untuk menghasilkan output institusi sesuai profil lulusan telah ditetapkan dan direalisasikan dalam pelaksanaan kurikulum program studi. Direkomendasikan agar usaha untuk peningkatan kinerja disinergikan dengan peningkatan status akreditasi program studi dan AIPT institusi Universitas. Termasuk didalamnya kegiatan promosi dan penempatan tempat kerja sebagai rumah kedua.

\section{SIMPULAN}

Sebagai penutup, dapatlah disimpulkan bahwa peningkatan kinerja dosen, mahasiswa, dan pegawai perlu 
kebijakan institusi fakultas maupun pendukung manajerial dan operasional yang diperlukan untuk mengembangkan prodi di setiap jurusan untuk memenuhi kebutuhan guru dan SDM pelaku kegiatan ekonomi di dunia usaha dan industry (DUDI) terus meningkat. Kedua, tatalaksana administrasi input-prosesoutput informasi manajemen berbasis teknologi informasi (TI) di lingkungan FE untuk menunjang kegiatan pembelajaran dan administrasi program belum optimal. Ketiga, kinerja dosen dan pegawai administrasi fakultas berbasis TI bervariasi volume dan mutunya. Keempat, pola manajemen waktu kegiatan organisasi kemahasiswaan di bidang ekstraakademik berbagi dengan tupoksi sehingga diperlukan kesamaan persepsi dan pengaturan kegiatan yang proporsional terhadap penyelesaian masalah-masalah akademik dan nonakafrmik. Kelima, kinerja civitas akademika untuk menghasilkan output institusi sesuai profil lulusan telah ditetapkan dan direalisasikan dalam pelaksanaan kurikulum program studi.

Dari aspek pemenuhan saranaprasarana, disarankan agar strategi dan pengembangan Fakultas ke depan hendaknya lebih diarahkan untuk peningkatan pemanfaatan sarana dan prasarana perkuliahan. Penambahan fisik bangunan untuk menunjang proses belajar mengajar seperti penambahan ruang kelas, laboratorium dan perpustakaan sangat diperlukan. Peningkatan kualitas dan kelengkapan prasarana juga sangat diperlukan terutama untuk meningkatkan kenyamanan dalam proses belajar mengajar. Pelaksanaan pengembangan juga tidak hanya dalam hal pengembangan gedung saja namun juga diupayakan dalam hal pengembangan alat-alat laboratorium yang akan diupayakan selalu diperbaharui sesuai dengan perkembangan teknologi dan keperluan pasar kerja. Peningkatan prasarana untuk meningkatkan kualitas proses belajar mengajar juga akan diupayakan dalam hal peningkatan kualitas dan kuantitas bahan ajar seperti buku ajar, buku teks, jurnal, kertas kerja, dan penyusunan perangkat pembelajaran berbasis $\mathrm{TI}$.

Dari aspek SDM, daya Staff Dosen di Fakultas Ekonomi yang sekarang perlu ditingkatkan baik dari segi kuantitas maupun kualitasnya. Peningkatan kualitas sudah dimulai dilaksanakan dengan studi lanjut ke jenjang S2 maupun S3 serta dengan melibatkan staff dosen untuk mengikuti pelatihan-pelatihan baik bersifat akademik maupun profesional, sedangkan untuk peningkatan kuantitasnya diharapkan dengan adanya pengangkatan staf dosen baru. Hal ini dikuatkan oleh adanya minat mahasiswa yang semakin meningkat sejak dua tahun terakhir semakin banyak mengakibatkan Fakultas Ekonomi dan Bisnis semakin dikenal dikalangan masyarakat hal ini terbukti jurusan-jurusan di non pendidikan dan pendidikan di lingkungan fakultas ekonomi dan bisnis tidak pernah sepi peminat pada setiap tahunnya. Promosi Fakultas menjadi kegiatan mutlak dan rutin yang harus dilakukan setiap tahun khususnya ke sekolah-sekolah yang berpotensi meneruskan pendidikan tingginya di Bali dan Nusa Tenggara.

\section{DAFTAR PUSTAKA}

Mayer, Robert R dan Ernest Greenwood (2014). Rancangan Penelitian Kebijakan Sosial (terjemahan). Seri Pustaka Teknologi Pendidikan. Jakarta: CV Rajawali Press

Naskah Akademik Pembukaan FE Undiksha (2012), Tim Perencanaan dan Pengembangan Universitas Pendidikan Ganesha Singaraja

Prasetyo, Hanung Nindito, Eka Widhi Yunarso, dan Heru Nugroho (2014) Implementasi Sistem Remunerasi Berbasis Kinerja Di Perguruan Tinggi (Studi Kasus Fakultas IImu Terapan Universitas Telkom D/H Politeknik Telkom). Prosiding Seminar Nasional Manajemen Teknologi XX Program Studi MMT- 
ITS, Surabaya 1 Februari 2014. ISBN : 978-602-97491-9-9

Renstra Universitas Pendidikan Ganesha 2015-2020 (Edisi Revisi 2015). Bagian Penerbitan Universitas Pendidikan Ganesha

Renstra Fakultas Ekonomi dan Bisnis Universitas Pendidikan Ganesha 2012-2015.Tim Perencanaan dan Pengembangan FEB Universitas Pendidikan Ganesha Singaraja

Renstra Fakultas Ekonomi Universitas Pendidikan Ganesha 2016-2020. Tim Perencanaan dan Pengembangan FE Universitas Pendidikan Ganesha Singaraja

Suharsono, Naswan (2016). Pengembangan Model Manajemen Berbasis Kinerja di Fakultas Ekonomi Undiksha. Laporan Penelitian, Lembaga Penelitiaan Undiksha.

Suharsono, Naswan (2008). Implementasi Model Pembelajaran Multimedia dengan CD-interaktif untuk Mengembangkan Budaya Kewirausahaan Mahasiswa Perguruan Tinggi. Jurnal Pendidikan dan Pengajaran. Edisi Khusus. Desember 2008. Vol. 41: 1422-1435.

\section{Suharsono, Naswan (2011). Model Jaringan Website untuk Meningkatkan Efektivitas Perkuliahan Teknologi Pembelajaran Program Pascasarjana Undiksha Laporan Penelitian. Singaraja: Lembaga Penelitian Universitas Pendidikan Ganesha}

$\begin{array}{cr}\text { Suharsono, Naswan } & (2012) . \\ \text { Pengembangan } & \text { Perangkat } \\ \text { Pembelajaran } & \text { Teknologi } \\ \text { Pembelajaran, } & \text { Multimedia, } \\ \text { Perencanaan dan Pengembangan } \\ \text { Kurikulum, serta } & \text { Pembelajaran } \\ \text { Inovatif Berbasis } & \text { e-Learning. }\end{array}$

$\begin{array}{ll}\text { Laporan Penelitian. } & \text { Singaraja: } \\ \text { Lembaga Penelitian } & \text { Universitas } \\ \text { Pendidikan Ganesha } & \end{array}$

Suharsono, Naswan (2013). Analisis Validasi Implementasi Perangkat Pembelajaran Teknologi Pembelajaran, Multimedia, Perencanaan dan Pengembangan Kurikulum, Pembelajaran Inovatif Berbasis e-Learning. Laporan Penelitian. Singaraja: Lembaga Penelitian Undiksha

Sujana, Edy; Ananta Wikrama TA, I Putu Gede Diatmika (2007). Kajian Kelayakan Pendirian Program Studi S1 Akuntansi pada Jurusan Akuntansi Fakultas Pendidikan IImu Pengetahuan Sosial Universitas Pendidikan Ganesha Singaraja. Laporan Penelitian. Singaraja: Lembaga Penelitian Universitas Pendidikan Ganesha

Sujana, Edy, Wayan Lasmawan, Naswan Suharsono, dan I Putu Gede Parma (2013). Model Kebijakan Manajemen Institusi Untuk Pembukaan Program Studi Baru dan Pengembangan Laboratorium FE Terintegrasi. Singaraja: Laporan Penelitian DIPA Undiksha

Weinfield, adi, Richard W. Fuller dan Allan M. Williams (2010), Clustering and compatibility between tourism attractions, International Journal of Tourism Research Vol 12, (1). pages 1-16, January/FEruary 2010 